\title{
Imágenes de Fluorescencia de Rayos $X$ en Huesos Humanos y su Potencial Aplicación in vivo
}

\author{
Images of X-Ray Fluorescence in Human Bones and Their Potential Application in vivo
}

\author{
*R. G. Figueroa; *," E. Lozano \& ${ }^{* * *}$ M. A. Flores
}

FIGUEROA, R. G.; LOZANO, E. \& FLORES, M. A. Imágenes de fluorescencia de rayos X en huesos humanos y su potencial aplicación in vivo. Int. J. Morphol., 29(3):1000-1006, 2011.

RESUMEN: El conocimiento de la concentración y la distribución espacial de los elementos químicos presentes en diferentes órganos y tejidos resulta un parámetro útil para el diagnóstico de determinadas patologías o niveles por sobre los límites tolerables, por lo tanto el conocimiento de los elementos presentes en un tejido vivo, su concentración y distribución espacial podría proporcionar información relevante respecto del estado de salud de un individuo. Se presenta una aplicación de una nueva técnica de fluorescencia rayos $\mathrm{X}$ dispersiva en energía mediante barrido, la cual se puede aplicar a muestras de diferente composición y forma, a diferencia de, la mayoría de las técnicas existentes, que son aplicables sólo a muestras planas. Esta técnica permite la obtención de imágenes bidimensionales de los elementos químicos presentes en las muestras de un modo tanto mono como multielemental. En este trabajo es aplicada a un conjunto muestras óseas humanas y tarso y dedos de Gallus gallus (pollo) faenado, obteniéndose una distribución espacial 2D con diferentes niveles de intensidad fluorescente dependiendo del elemento detectado y de su concentración. Las imágenes logradas consideran áreas de hasta104 $\mathrm{mm}^{2}$, con una resolución espacial de hasta $0,25 \mathrm{~mm}^{2}$ y en un tiempo de adquisición de alrededor de 20 min. También se lleva a cabo un cálculo de la dosis de la radiación asociada a este tipo de análisis XRF, encontrándose que los niveles aplicados para la obtención de una imagen XRF son tolerables. Lo anterior permite concluir que sería posible el uso de esta técnica para una aplicación in vivo.

\section{PALABRAS CLAVE: Imágenes con rayos X; Análisis XRF in vivo}

\section{INTRODUCCIÓN}

La determinación de los elementos químicos presentes en órganos y tejidos se considera un buen indicador de ciertas patologías e intoxicaciones. El análisis de fluorescencia de rayos X (XRF) en vivo, técnica descrita por primera vez por Ahlgren et al. (1976), permite la detección de elementos presentes en el organismo que podrían provocar estados patológicos. Entre éstos la presencia de plomo $(\mathrm{Pb})$ en el organismo humano, y particularmente en el tejido óseo, es uno de los más estudiados (Sanin et al., 1998; Jurkiewicza et al., 2005; Gerhardsson et al., 2005). La exposición prolongada al plomo tiene efectos deletéreos en diversos sistemas ya que al competir con elementos esenciales tales como calcio y zinc altera procesos enzimáticos y metabólicos
(Téllez \& Bautista, 2005). Otro ejemplo de lo anterior lo constituye el cobre $(\mathrm{Cu})$, al cual se le asocia con el cáncer por presentarse en altas concentraciones en células malignas, entre 1.5 a 3 veces respecto de sus valores normales (Anshul \& Mumper, 2009). Por otra parte, el estroncio (Sr) estable posee efectos anti-osteoporóticos, ya que inhibe la resorción ósea y contribuye a aumentar la masa ósea, en contraste con el estroncio radiactivo, el cuál induce efectos tóxicos en las células óseas (Pejovic et al., 2004; Pors Nielsen, 2004; Marie, 1996; Marie et al. 2001). Debido a que puede ejercer efectos tanto benéficos como tóxicos en los huesos, es necesario evaluar su concentración in vivo (Pejovic-Milic, 2004). Mediante un dispositivo portátil la técnica de fluores-

\footnotetext{
* Departamento de Física, FICA, Universidad de La Frontera, Temuco, Chile,

** Instituto Nacional del Cáncer, Santiago, Chile.

*** Departamento de Odontología, Facultad Medicina Universidad de La Frontera, Temuco, Chile. Este trabajo fue financiado por el FONDECYT a través del Proyecto 1080306
} 
cencia de rayos $\mathrm{X}$ dispersiva en energía (EDXRF) ha sido utilizada en vivo para determinar concentraciones de fierro $(\mathrm{Fe})$ en la sangre por sobre los niveles normales a través de la piel, lo que facilitaría el seguimiento de pacientes con b talasemia y hemocromatosis, así como también ha permitido la determinación en vivo de la concentración de mercurio $(\mathrm{Hg})$ en el riñón en trabajadores laboralmente expuestos a este elemento (Estevam \& Appoloni, 2009). Por otra parte, se han reportado estudios en vivo de carácter multielemental para determinar la concentración de elementos tanto mayoritarios como a nivel de trazas, siendo detectados elementos tales como calcio $(\mathrm{Ca})$, estroncio $(\mathrm{Sr})$, cinc $(\mathrm{Zn})$, cadmio $(\mathrm{Cd})$ y plomo $(\mathrm{Pb})$ (Borjesson et al., 1995; Borjesson et al., 1998; Zaichick et al., 1999; Börjesson \& Mattsson, 1995).

En general la técnica XRF in vivo se enfoca en la determinación de la concentración de elementos pesados en hueso, utilizando como blanco principal la tibia y las falanges óseas. Hasta ahora no se conocen trabajos relacionados con la distribución espacial de las concentraciones medidas de los elementos detectados mediante las técnicas convencionales relacionadas con XRF in vivo.

En este trabajo se presenta la aplicación de esta metodología a un conjunto muestras óseas humanas y al tarso y dedos de un Gallus gallus (pata de pollo) faenado, con el propósito de determinar su capacidad de detección, la distribución de elementos químicos presentes en ellas y su factibilidad para obtener imágenes XRF en vivo. Los autores basan este trabajo en un dispositivo de fluorescencia de rayos-X mediante barrido (XRFSD) que incluye el desarrollo de un software y un firmware, que permite realizar barridos $2 \mathrm{D}$ en áreas de hasta $100 \mathrm{~cm}^{2}$.

\section{MATERIAL Y MÉTODO}

Se utilizó un espectrómetro de EDXRF como dispositivo de barrido, que se le denomió XRFSD, especialmente diseñado y en proceso de obtención de una patente de invención. Este es capaz de adquirir imágenes de la distribución $2 \mathrm{D}$ de elementos químicos con $\mathrm{Z} \geq 12$; la muestra analizada puede tener cualquier forma y un tamaño máximo de $104 \mathrm{~mm}^{2}$. La metodología de adquisición consiste en un barrido paso a paso rectangular del cabezal (fuente detector) del brazo robótico del XRFSD, a una distancia promedio de aproximadamente $1,5 \mathrm{~cm}$ por sobre la superficie de la muestra. Esta distancia es elegida para una muestra plana con un criterio de máximo acercamiento sin interferencia entre el tubo y el detector y con la máxima intensidad posible a fin de asegurar una buena estadística de conteo por cada punto de barrido.
Para cada muestra a analizar se define la zona de interés según forma y dimensiones de la misma, y por lo tanto al comienzo de cada adquisición son establecidos: el número de puntos por lado, el tiempo de adquisición por punto, el paso y el área de barrido. De acuerdo al paso y al diámetro de colimación la resolución espacial puede llegar a $0,25 \mathrm{~mm}^{2}$ por píxel. El tiempo mínimo de captura espectral XRF puede llegar hasta $1 \mathrm{~ms}$ por punto con 256 canales de energía por espectro, dentro de los cuales es posible diferenciar todos los elementos químicos detectados, gracias a la buena resolución en energía (136 eV) de la unidad de detección (SDD) del dispositivo. La distancia MTRX-muestra va desde un mínimo de $1,4 \mathrm{~cm}$ hasta $2 \mathrm{~cm}$ y la distancia muestraSDD va desde $1,6 \mathrm{~cm}$ hasta $2,2 \mathrm{~cm}$.

El XRFSD posee un software para el procesamiento de los datos almacenados en una matriz de nxm puntos, por cada punto de escaneo (x,y) guarda el espectro EDXRF asociado, entregando finalmente un único espectro que corresponde a la suma de todos los espectros generados durante el barrido, del cual se seleccionan los picos de los elementos químicos de interés detectados para visualizar las imágenes XRF correspondientes.

La muestra a ser analizada se suspende en el aire por medio de un pequeño y delgado soporte de bajo Z, de esta manera se consiguen imágenes XRF con un contorno limpio y sin la interferencia del sustrato.

Las muestras utilizadas en este trabajo corresponden a huesos humanos tales como falanges de mano, patela, fémur, fíbula y mandíbula con remanentes dentarios. También son analizados en el tarso y dedos de un Gallus gallus con su correspondiente tejido blando. Dados estos materiales, se definen las condiciones de referencia para la obtención de las imágenes de los diferentes elementos presentes en las muestras.

En una primera etapa se adquieren espectros XRF en un conjunto de muestras óseas con el propósito de determinar los elementos que es posible detectar, las cuales son irradiadas en una zona fija. A continuación se procede a realizar adquisiciones con barridos XRF, primero a las falanges de una mano y parte de una mandíbula humana. Finalmente, con el propósito de aproximarse a una fluorescencia in vivo, se realiza el mismo procedimiento anterior pero en el tarso y dedos de un Gallus gallus.

Todas las imágenes originalmente logradas mediante el XRFSD son procesadas mediante un software Image $\mathbf{J}$ (NIH, 2011), el cual permite realizar una reducción de malla, un suavizado y una sustracción de fondo, entre otros tratamientos, para mejorar la calidad de la imagen y definir 
las zonas en las cuales los elementos están presentes. Este último procedimiento es fundamental en aquellos elementos cuyos picos asociados presentan una baja relación señal a ruido. Todas las imágenes se normalizan a su intensidad máxima en una escala de 0 a 240 niveles sin embargo en aquellos elementos donde hubo una significativa sustracción de fondo la escala va del nivel de corte a 240.

\section{RESULTADOS}

Se consideran seis muestras de huesos de diferente tipo, en las cuales se detectan un total de 14 elementos: $\mathrm{Mg}$, $\mathrm{Al}, \mathrm{P}, \mathrm{K} \mathrm{Ca}, \mathrm{Ti}, \mathrm{Cr}, \mathrm{Fe}, \mathrm{Ni}, \mathrm{Cu}, \mathrm{Zn}, \mathrm{Pb}, \mathrm{Sr}$ and $\mathrm{Zr}$, cuyas intensidades relativas respecto de la intensidad total corresponde a la suma de los picos fluorescentes, se muestran en la Tabla I.

En la Figura 1 se presenta el espectro XRF integral correspondiente a una muestra de falanges de una mano hu- mana. En la Figura 2 se muestra una fotografía de la misma muestra anterior, junto con las correspondientes imágenes XRF de algunos de los elementos detectados en ella, tales como P, Ca, Fe y Zn. En la Figura 3 se muestran las imágenes XRF correspondientes a una parte de una mandíbula humana en donde es posible observar, además de la presencia de piezas dentarias, que el espectro XRF asociado en este caso es similar al encontrado en las falanges de la mano humana. Finalmente, en las Figuras 4 y 5 se presentan respectivamente el espectro y las imágenes XRF correspondientes al tarso y dedos de un Gallus gallus. En este caso el espectro XRF es notablemente diferente a los demás espectros obtenidos de las piezas óseas anteriores. Esta diferencia se debe principalmente a un aumento del fondo del espectro debido a la presencia de tejido blando, el cual genera una mayor dispersión de la radiación X que en ella interactúa.

Las muestras son irradiadas con una tasa de dosis previamente calculada, aproximadamente igual a $20 \mu \mathrm{Gy} / \mathrm{s}$, con un haz colimado de $2 \mathrm{~mm}$ a $1.5 \mathrm{~cm}$ de la muestra y con una incidencia de $45^{\circ}$.

Tabla I. Intensidades relativas medias respecto de la suma de todas las intensidades de los picos principales (Ka y La) asociados a los elementos detectados en las muestras óseas medidas.

\begin{tabular}{|c|c|c|c|c|c|}
\hline \multirow{2}{*}{ Mayoritarios } & & & & & \\
\hline & $\mathrm{Ca}$ & $\mathbf{Z n}$ & $\mathrm{Fe}$ & $\mathbf{P}$ & $\mathrm{Sr}$ \\
\hline \multirow{3}{*}{ Intermedios } & 0,800 & 0,048 & 0,028 & 0,027 & 0,025 \\
\hline & $\mathbf{N i}$ & $\mathbf{Z r}$ & $\mathbf{P b}$ & & \\
\hline & 0,015 & 0,016 & 0,009 & & \\
\hline \multirow[t]{2}{*}{ Trazas } & Mn & Ti & Cl & $\mathbf{S}$ & $\mathbf{V}$ \\
\hline & 0,007 & 0,006 & 0,005 & 0,003 & ----- \\
\hline
\end{tabular}

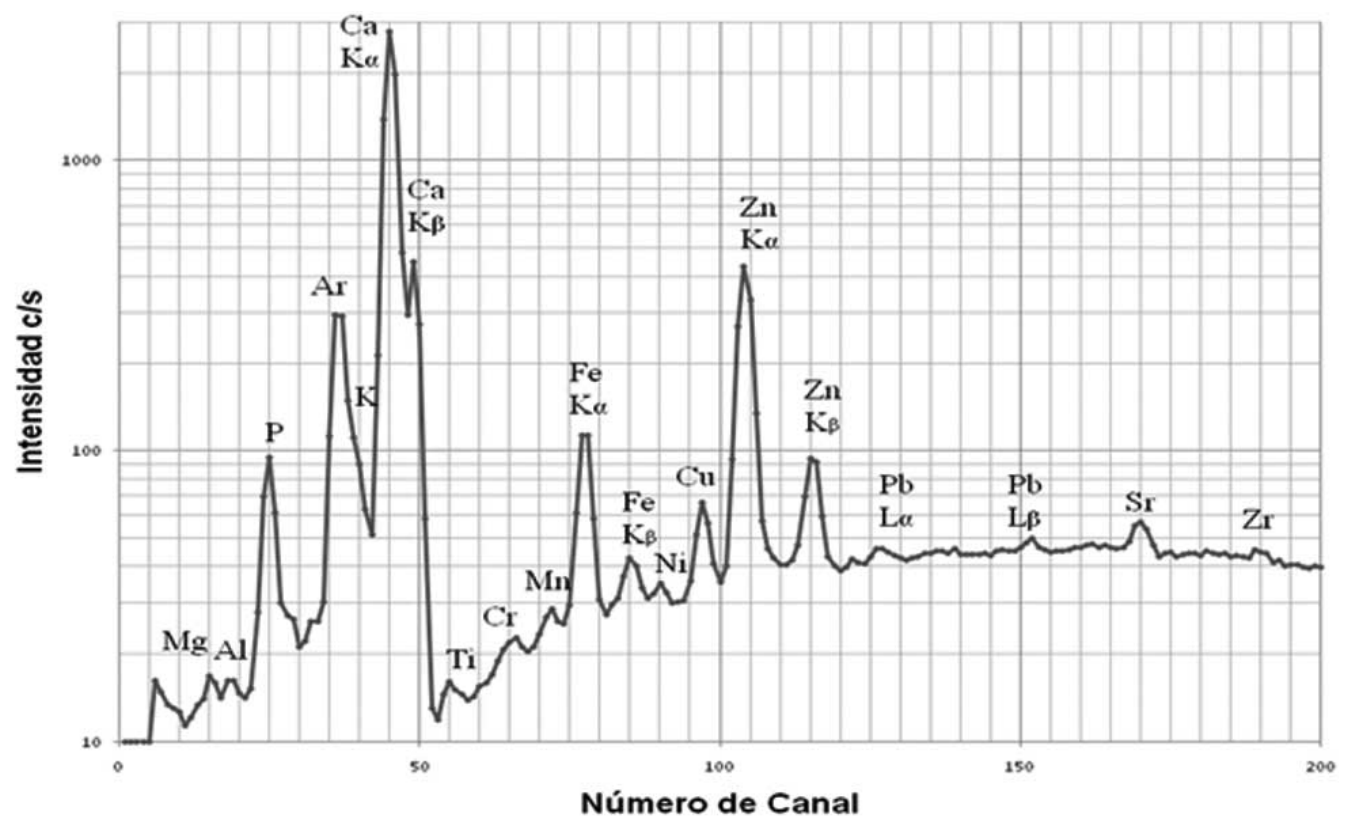

Fig. 1. Espectro XRF integral del esqueleto de la mano humana en los que se muestra la presencia de 14 elementos, los cuales son $\mathrm{Mg}, \mathrm{Al}$, $\mathrm{P}, \mathrm{K} \mathrm{Ca}, \mathrm{Ti}, \mathrm{Cr}, \mathrm{Fe}, \mathrm{Ni}$, $\mathrm{Cu}, \mathrm{Zn}, \mathrm{Pb}, \mathrm{Sr}$ and $\mathrm{Zr}$. 


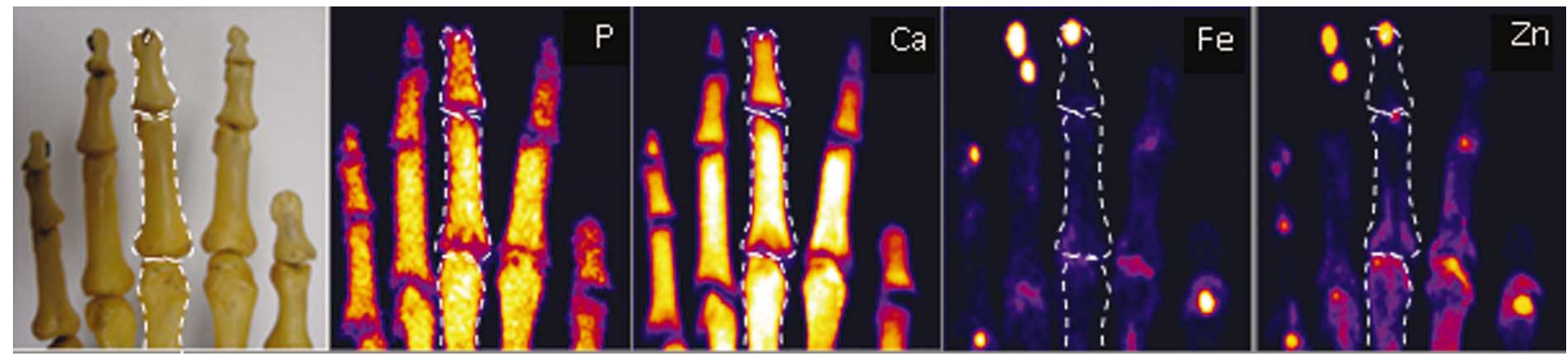

Fig. 2. Imágenes XRF en intensidades relativas de los elementos $\mathrm{P}, \mathrm{Ca}, \mathrm{Fe}$ y $\mathrm{Zn}$ detectados en el esqueleto de una mano humana con su correspondiente imagen óptica visible.

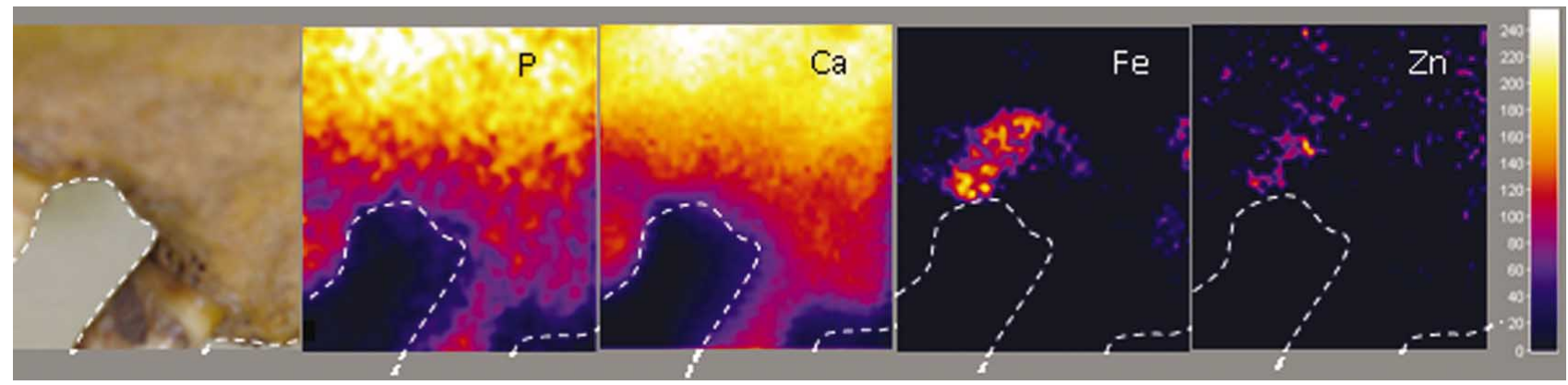

Fig. 3. Imágenes XRF en intensidades relativas de los elementos $\mathrm{P}, \mathrm{Ca}, \mathrm{Fe}$ y $\mathrm{Zn}$ detectados en el hueso alveolar mandibular cercano al primer molar con su correspondiente fotografía visible.

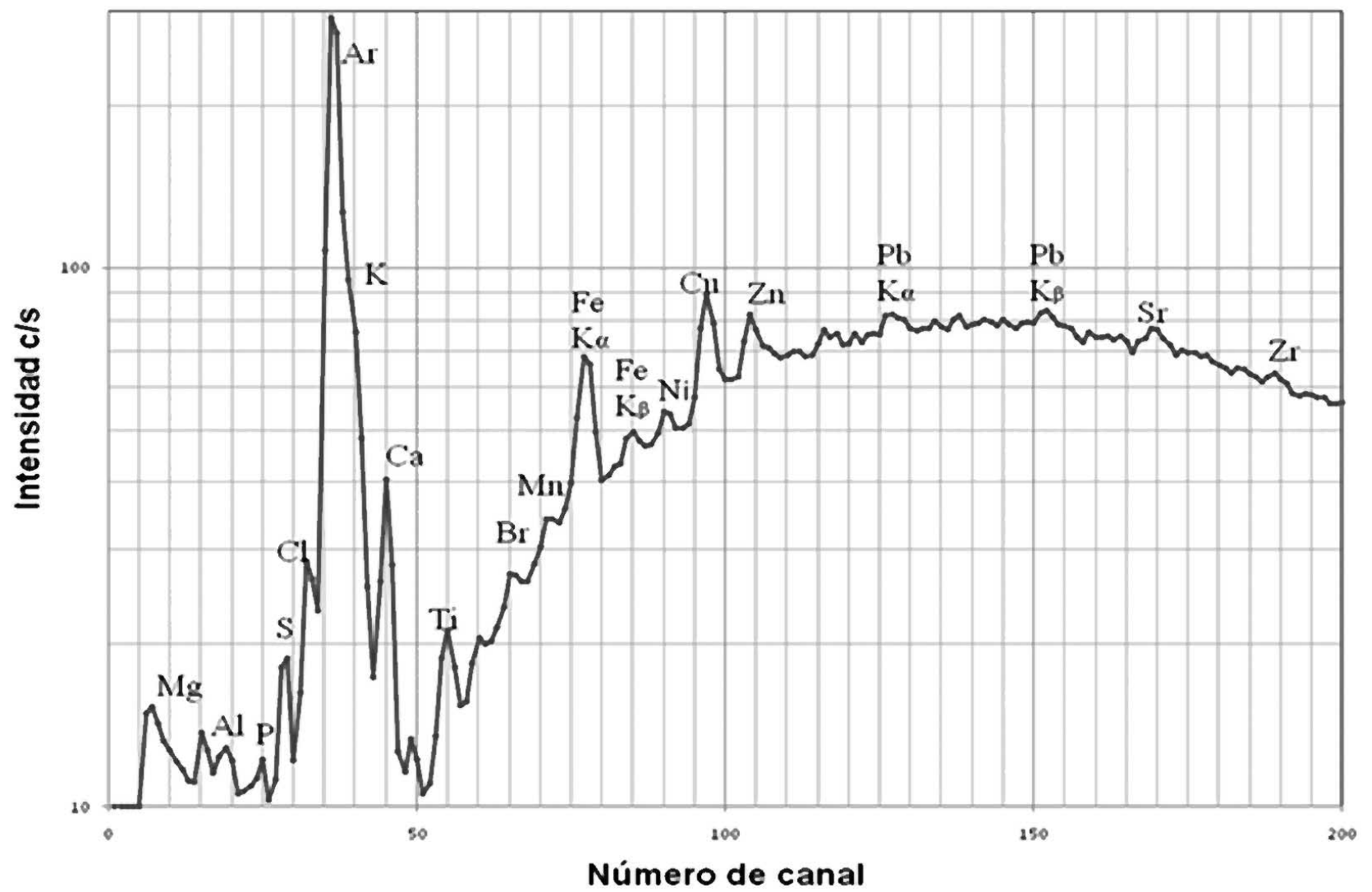

Fig. 4. Espectro XRF integral en el tarso y dedos de un Gallus gallus en los que se muestra la presencia de 16 elementos químicos: Mg, Al, P, S, Cl, K, Ca, Ti, Br, Mn, Fe, Ni, Cu, Zn, Pb, Sr y Zr. 


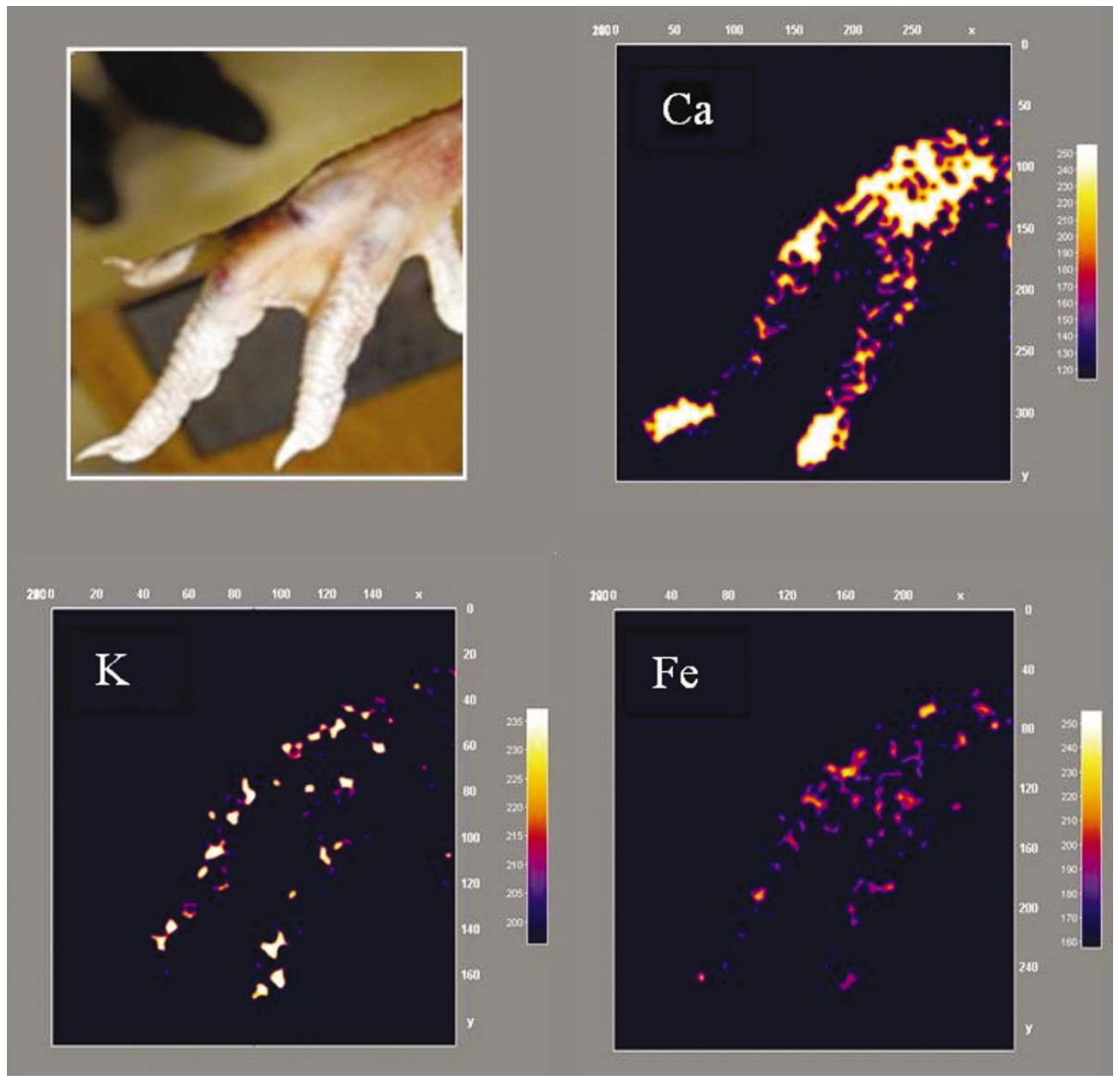

Fig. 5. Imágenes XRF en intensidades relativas de los elementos $\mathrm{P}, \mathrm{Ca}$, y Fe detectados en el tarso y dedos de un Gallus gallus con su correspondiente fotografía visible.

\section{DISCUSIÓN}

En todas la muestras óseas analizadas se observa una mayor cantidad en la intensidad fluorescente asociada al calcio en el hueso animal respecto de los huesos humanos, y dentro de estos es relativamente uniforme, con excepción del calcio en la mandíbula, que presenta una mayor proporción de intensidad, lo que indicaría una mayor presencia del elemento en cuestión. Los elementos $\mathrm{P}$, Ni y Sr se encuentran en proporciones similares en los diferentes huesos analizados, lo cual muestra que estos elementos se correlacionan con el $\mathrm{Ca}$. Por otra parte, los elementos $\mathrm{Fe}, \mathrm{Cu}, \mathrm{Zn}$ y $\mathrm{Pb}$ presentan significativas diferencias en las muestras analizadas, lo cual indicaría una escasa o nula correlación con la composición elemental de la matriz ósea y por lo tanto su presencia puede ser explicada por otros procesos o por contaminación o exposición a estos elementos. Además puede observarse en las imágenes XRF correspondientes a las falanges que los elementos que presentan una mayor variabilidad, tales como el Fe y el Zn, muestran distribuciones no uniformes.
Las imágenes XRF que se presentan en la Figura 2 corresponden a una muestra en la que se detectan 14 elementos químicos. Los que se muestran son aquellos que presentan picos con mayor intensidad y relación señal a ruido y corresponden al P, Ca, Fe y Zn. La imagen correspondiente al P muestra que este elemento está presente en toda la matriz ósea de modo aproximadamente uniforme en todas las falanges. La imagen del $\mathrm{Ca}$ corrobora la mayor intensidad de este elemento, mostrada en el espectro XRF de la Figura 1 , y la uniformidad del mismo como elemento principal en la matriz ósea. Con respecto al $\mathrm{Fe}$ se observa una imagen de mucho menor intensidad que las anteriores y que este elemento de distribuye de un modo muy diferente; también es posible apreciar allí zonas muy intensas, las cuales corresponden a los alambres metálicos que unen las falanges, lo cual muestra que la técnica es capaz de diferenciar elementos ajenos a la matriz ósea bajo análisis. Finalmente es posible observar la imagen XRF correspondiente al Zn, donde se observa un patrón de distribución algo más intenso y diferente al anterior. Se aprecia que este elemento tiende a acumularse en la zona cercana a la epífisis de las falanges y 
a lo largo de éstas en un modo no uniforme. Al igual que en el caso del Fe, aquí también aparecen zonas de alta intensidad y en las mismas posiciones, lo cual indica que el alambre utilizado también posee $\mathrm{Zn}$.

Con respecto a las imágenes XRF que se observan en la Figura 3, en general se puede apreciar un comportamiento similar al observado en la figura anterior pero con algunas diferencias destacables, como por ejemplo que el Fe aparece localizado en una zona bien definida en la base dentaria, sin embargo éste no se observa en la pieza dentaria misma. Por su parte el Zn muestra una localización dispersa no homogénea. Por su parte el Ca y el P siguen apareciendo de un modo homogéneo, como en el caso de las falanges de la mano.

En la Fig. 4 se observan las imágenes XRF del tarso y dedos de Gallus gallus, que muestran mapas de tres de los 17 elementos detectados, los que corresponden al $\mathrm{Ca}, \mathrm{K}$ y Fe. Este es el caso más cercano de lo que sería una fluorescencia de rayos $\mathrm{X}$ in vivo con seres humanos, ya que el tarso y dedos poseen un tejido similar. Aquí los efectos de dispersión inelástica se hacen notar debido a la presencia del tejido blando, lo que conlleva un empeoramiento de la relación señal a ruido en varios de los elementos detectados, como por ejemplo $\mathrm{Fe}, \mathrm{Cu}$, y $\mathrm{Zn}$ entre otros, los cuales presentan una imagen aparente del elemento de interés con mayor intensidad, superponiéndose en cada punto del material blando efectos que generan fotones fluorescentes y fotones dispersados (efecto Compton). Este problema de la separación pico-fondo se debe abordar en cada punto $(\mathrm{x}, \mathrm{y})$, restando el fondo a los fotones fluorescentes, lo que resulta una tarea de compleja resolución, dada la diversidad de formas en que puede presentarse la muestra y lo complejo que puede llegar a ser el cálculo del fondo en cada punto. Como una aproximación el software Image J (NIH, 2011) permite llevar a cabo una sustracción de fondo plana, cuyo punto de corte es variable. Aunque es posible calcular este punto, la descripción de este proceso está lejos del propósito de este trabajo. Las sustracciones de fondo que aquí llevan a cabo son más bien para destacar las zonas en donde los elementos se concentran.

Estas imágenes XRF se han obtenido con barridos paso a paso, lo cual conlleva una pérdida de tiempo en los desplazamientos entre punto y punto, que puede significar en algunos casos un tiempo adicional de hasta un $110 \%$ del tiempo neto. Para mejorar esto se está trabajando en un modo paso a paso con adquisición permanente, lo que reducirá considerablemente el tiempo total en la obtención de las imágenes y una menor dosis de radiación al individuo que se someta a este tipo de análisis.

En las muestras óseas utilizadas se detectó el contenido de plomo $(\mathrm{Pb})$, como se muestra en la Fig. 1, elemento de gran interés y estudiado por varios grupos de trabajo debido a sus implicaciones para la salud humana, como se mencionó anteriormente. Dada la intensidad que tiene el mini tubo de rayos $\mathrm{X}$ utilizado en el trabajo, sólo es posible obtener fluorescencia característica debido a las capas La del plomo, obteniéndose cuentas insuficientes en el tiempo que se realiza el barrido para la obtención de una imagen de su distribución bidimensional. Obtener una imagen de este elemento requiere tiempos de a lo menos 1 segundo por punto, intervalo necesario para que el pico característico del mismo sea identificado. Lo anterior implica tener mucho tiempo la muestra en exposición para realizar un barrido en áreas grandes, por lo tanto se requiere para este caso, trabajar con un colimador de mayor diámetro y tubos de mayo intensidad, para así definir zonas macro en que el plomo puede estar en mayor concentración.

\section{CONCLUSIONES}

Se ha mostrado que es posible detectar y determinar la distribución de elementos químicos presentes en muestras óseas de forma irregular y gran tamaño a través de imágenes XRF, obtenidas mediante un dispositivo XRFSD, especialmente diseñado para tal propósito. Las imágenes correspondientes a los elementos $\mathrm{Ca}$, P, Fe y Zn son fácilmente obtenidas a partir de una sola adquisición multielemental en un tiempo total de alrededor de $20 \mathrm{~min}$. Otros elementos detectados también pueden ser mapeados, pero se requieren mayores tiempos de adquisición.

Se lograron imágenes de K, Ca y Fe en el tarso y dedos de un Gallus gallus faenado sin embargo en este caso es necesario un mayor procesamiento de los datos debido al incremento del fondo generado por un aumento de los fotones dispersados en el tejido blando.

El sistema es capaz de adquirir imágenes XRF multielementales en diversos tiempos de barrido, que dependen tanto de las concentraciones como del paso y del área de barrido, entre otros parámetros. Los tiempos por imagen pueden variar desde unos pocos segundos a varios minutos u horas según sea el caso, sin embargo cada espectro multielemental puede lograrse con tiempos mínimos de hasta $1 \mathrm{~ms} / \mathrm{p}$

Las dosis mínimas asociadas para la obtención de una imagen XRF están dentro de niveles de radiación tolerables para una aplicación in vivo, por lo tanto, es posible utilizar esta técnica para obtener imágenes XRF de la distribución de los elementos químicos presentes en huesos y órganos cercanos a la superficie de la piel. A su vez, la técnica permite explorar la presencia de más un elemento simultáneamente, dependiendo del área de selección espectral que se elija. 
FIGUEROA, R. G.; LOZANO, E. \& FLORES, M. A. Images of X-Ray fluorescence in human bones and their potential application in vivo. Int. J. Morphol., 29(3):1000-1006, 2011.

SUMMARY: The knowledge of the concentration and spatial distribution that chemical elements present in different organs and tissues is a useful parameter for diagnosis of certain diseases or element levels above limits accepted as healthy. Therefore, development of techniques to identify the chemical elements present in a living tissue and obtaining information about their concentration and spatial distribution might be relevant to determine an individual's health status. This work presents an application of a new X-ray fluorescence technique, energy dispersive by scanning, which can be applied to samples of different composition and shape, unlike most of the existing techniques, only applicable to flat samples. This technique allows the acquisition of two-dimensional images of the chemical elements present in a sample in both mono and multielemental mode. In this work the technique is applied to a set of human bone samples and tarsus and fingers of a dead Gallus gallus (chicken), obtaining a 2D spatial distribution with different levels of fluorescence intensity, depending on the detected element and its concentration. The acquired images consider areas up to $104 \mathrm{~mm}^{2}$, with a spatial resolution of $400 \mathrm{~mm}^{2}$ and an acquisition time of about 20 min. Calculations of the radiation dose associated with this type of XRF analysis were also carried out, and the findings show that the levels applied to obtain an XRF image are tolerable. The latter leads to the conclusion that it would be possible to use this technique for an in vivo application.

KEY WORD: Bones XRF images; in vivo XRF

\section{REFERENCIAS BIBLIOGRÁFICAS}

Ahlgren, L.; Liden, K.; Mattsson, S. \& Tejning, S. X-ray fluorescence analysis of lead in human skeleton in vivo. Scand. J. Work Environ. Health., 2:82-6, 1976.

Anshul, G. \& Mumper, R. Elevated copper and oxidative stress in cancer cells as a target for cancer treatment. Cancer Treat. Rev., 35:32-46, 2009.

Borjesson, J.; Barregard, L.; Sallsten, G.; Schutz, A.; Jonson, R.; Alpsten, M. \& Mattsson, S. In vivo XRF analysis of mercury: the relation between concentrations in the kidney and the urine. Phys. Med. Biol., 40(3):413, 1995.

Börjesson, J. \& Mattsson, S. Toxicology; In vivo x-ray fluorescence for the assessment of heavy metal concentrations in man. Appl. Radiat. Isot., 46(6-7): 571-6, 1995.

Börjesson, J.; Mattsson, S. \& Alpsten, M. Trace element concentrations studied in vivo using X-ray fluorescence analysis. Appl. Radiat. Isot., 49(5-6):437-45, 1998.

Estevam, M. \& Appoloni, C. R. Uso da fluorescência de raios X portátil (XRF) in vivo como técnica alternativa para acompanhamento dos níveis de ferro em pacientes com sobrecarga de ferro. Rev. Bras. Hematol. Hemoter., 31 (3):153-9, 2009.

Gerhardsson, L.; Akantis, A.; Lundstrom, N.G.; Nordberga, G.F.; Schutz, A. \& Skerfving, S. Lead concentrations in cortical and trabecular bones in deceased smelter workers. J. Trace Elem. Med. Biol., 19:209-15, 2005.

Jurkiewicza, A., Wiechulab, D., Nowaka, R., Loska, K. Lead content in the femoral heads of inhabitants of Silesia (Poland). J. Trace. Elem. Med. Biol., 19:165-70, 2005.

Marie, P. J. Effects of strontium on bone formation and bone cells. In: Neve, J., Chappuis, P., Lamand, M. Therapeutic uses of traces elements. Plenum Press, New York, 1996. pp 277-82.
Marie, P. J.; Ammann, P.; Boivin, G. \& Rey, C. Mechanisms of action and therapeutic potential of strontium in bone. Calcif. Tissue Int., 69:121-9, 2001.

National Institute of Health. (2011) Image J: Image Processing and Analysis in Java. Disponible en: http://rsbweb.nih.gov/ij/

Pejovic, A., Stronach, I.M., Gyorffy, J., Webber, C.E., Chettle, D.R. Quantification of bone strontium levels in humans by in vivo x-ray fluorescence. Med. Phys., 31(3): 528-38, 2004.

Pejovic-Milic A., Stronach I. M., Gyorffy J., Webber C. E., Chettle D. R. Quantification of bone strontium levels in humans by in vivo x-ray fluorescence. Med. Phys., 31(3): 528-38, 2004.

Pors Nielsen S. The biological role of strontium. Bone, 35:583-8, 2004.

Sanin, L. H., Gonzales, T., Romieu, I., Hernadez M. Acumulación del plomo en hueso y sus efectos en la salud. Salud Pública México, 40:359-68, 1998.

Téllez, J. \& Bautista, F. Exposición ocupacional a plomo: aspectos toxicológicos. Av. Enferm., 23(1):31-44, 2005.

Zaichick, V.; Ovchjarenko, N. \&, Zaichick, S. In vivo energy dispersive X-ray fluorescence for measuring the content of essential and toxic trace elements in teeth. Appl. Radiat. Isotopes, 50(2):283-93, 1999.

Dirección para correspondencia:

Prof. Dr. Rodolfo Figueroa

Departamento de Física, FICA

Universidad de La Frontera

Temuco - CHILE

Email: figueror@ufro.cl

Recibido : 02-05-2011

Aceptado: 03-06-2011 